\title{
Auger Electron Spectroscopy Analysis of Pit Initiation at MnS Nano-inclusions in Carbon Steel
}

\author{
J.G. Newman ${ }^{1}$, J.S. Hammond ${ }^{1}$, B. H. Davis ${ }^{2}$, Z. Suo ${ }^{2}$, I. Beech ${ }^{3}$, D. F. Paul ${ }^{1}$, and R. Avci ${ }^{2}$ \\ ${ }^{1}$ Physical Electronics, Chanhassen, MN 55317, USA \\ ${ }^{2}$ Montana State University, Bozeman, MT 59717, USA \\ ${ }^{3}$ University of Oklahoma, Norman, OH 73019, USA
}

Cold rolled carbon steel is a commonly used structural material in a wide variety of applications, including automotive, building construction, appliances, and even fuel storage tanks for naval ships. Although $\mathrm{Mn}$ is purposely added to carbon steel to getter problematic S impurities, it has long been postulated that $\mathrm{MnS}$ inclusions in carbon steel can act as sites of pitting initiation [1]. The propagation of pitting corrosion is relatively well understood; however, the initiation of pits is still a subject of controversy $[2,3]$. A careful study of pit initiation and propagation associated with sulfide inclusions has been lacking, partly because these inclusions are mostly submicron-sized and the evolution of their corrosion is difficult to monitor. An extremely small spectroscopic probe technique, such as Auger Electron Spectroscopy, capable of nanometer-scale resolution, is required to analyze and map out the elemental distributions within these submicron pits. Auger also has the surface sensitivity needed to detect very thin layers of contaminants associated with these surface-related phenomena.

This presentation will review the results of Auger studies of nano-inclusions on carbon steel surfaces prior to and following exposure of the steel to corrosive solutions. The nano-inclusions were carefully characterized using a field emission Auger nanoprobe with a spatial resolution of approximately $10 \mathrm{~nm}$ for imaging and spectroscopy.

Figure 1 shows an SEM image and Auger maps for a submicron sized MnS inclusion in carbon steel. Analysis of the inclusion by EDS showed the presence of only Mn and S while the more surface sensitive and spatially resolved Auger technique also detected $\mathrm{Cu}$ impurities and localized $\mathrm{O}$ patches $(\mathrm{Fe}$ and Mn oxides) on the inclusion. Thus, the chemical environment surrounding the inclusions is much more complex than originally thought. Other samples analyzed by Auger after exposure to artificial seawater provide evidence that, in corrosive environments, it is not the $\mathrm{MnS}$ inclusions that are initially dissolving but rather the areas surrounding the inclusions. The impact of this fundamental analysis [4] on the understanding of cold rolled steel pitting corrosion will be discussed.

\section{References:}

[1] G, Waglen. Corrosion Science, 14 (1974), p. 331-349.

[2] P. Schmuki, H. Hildebrand, A. Friedrich and S. Virtanen, Corrosion Science, 47 (2005): p. 12391250.

[3] J.E. Castle and Ruoru Ke, Corrosion Science, 30(4/5) (1990), p. 409-428.

[4] R. Avci, B.H. Davis, M.L. Wolfenden, I.B. Beech, K. Lucas, and D. Paul, Corrosion Science, 76 (2013), p. 267-274.

[5] Support by ONR (N00014-10-1-0946) is gratefully acknowledged. 


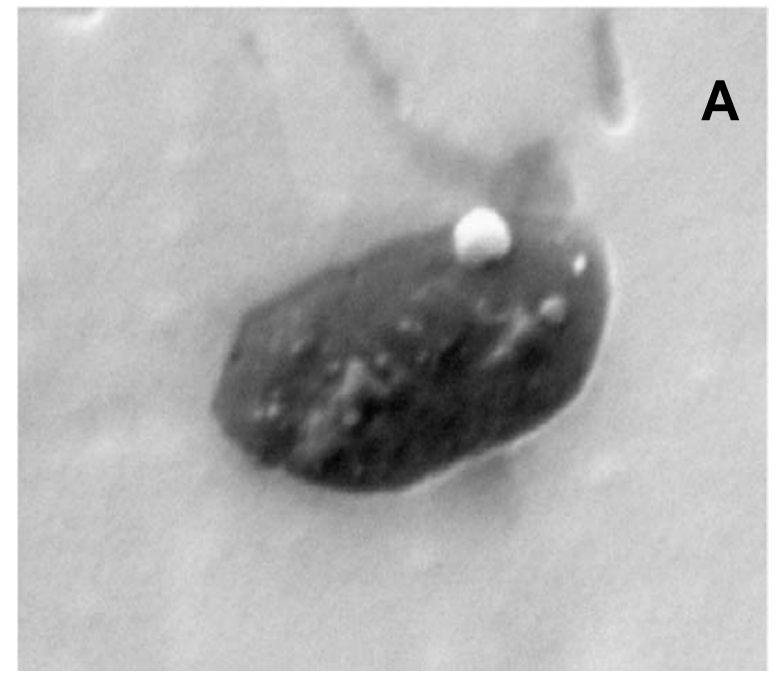

SEM, $10 \mu \mathrm{m}$ field of view

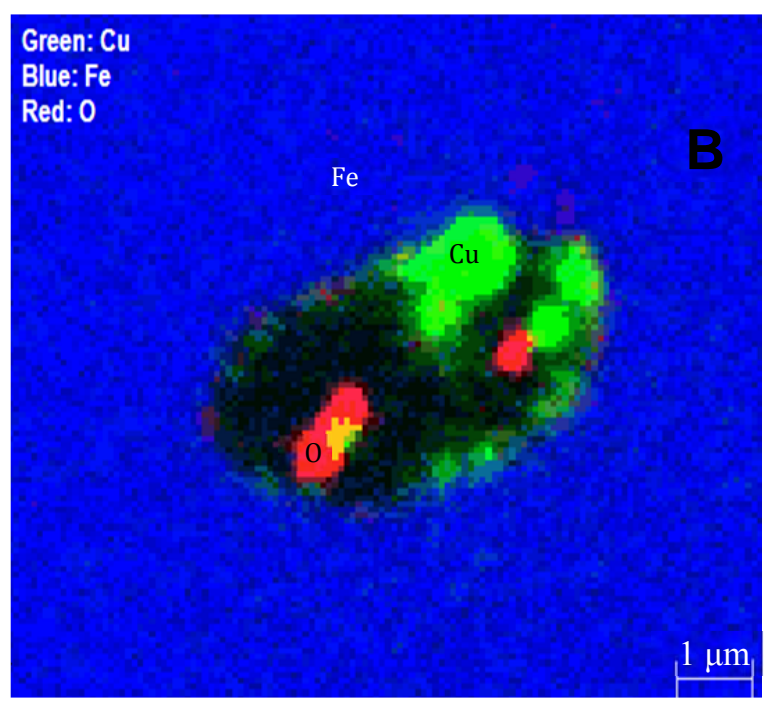

Auger Color Overlay of Fe, $\mathrm{O}$ and $\mathrm{Cu}$

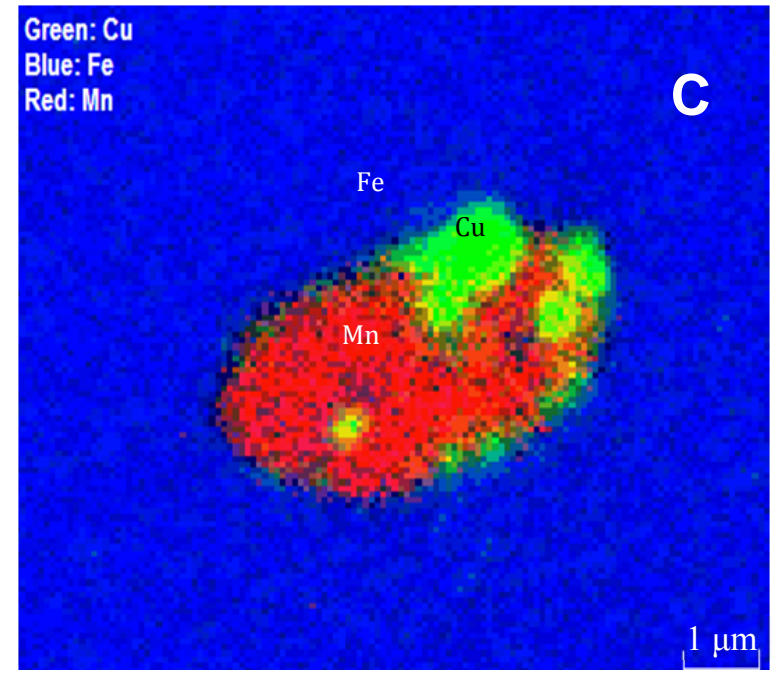

Auger Color Overlay of Fe, Mn and Cu

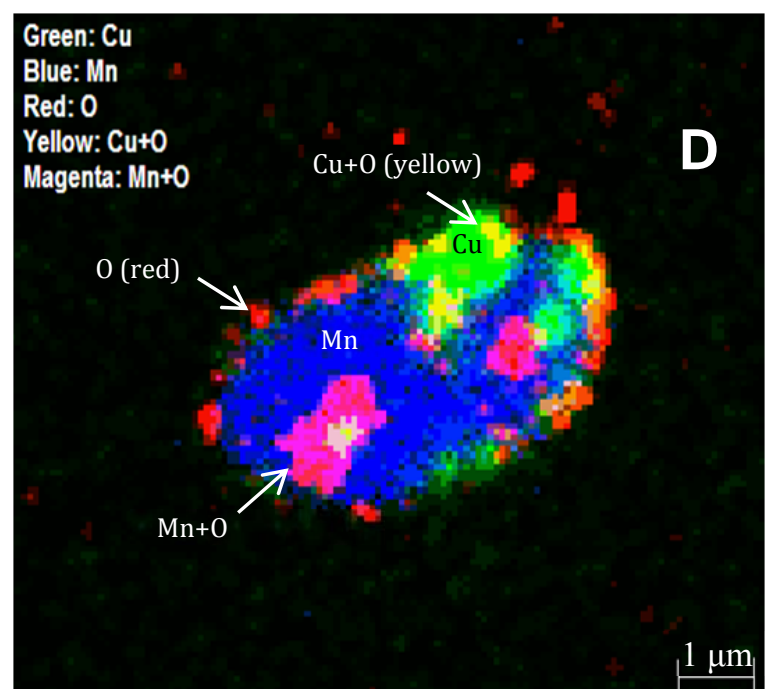

Auger Color Overlay of $\mathrm{Cu}, \mathrm{Mn}$ and $\mathrm{O}$

Figure 1. SEM image and Auger maps showing the distributions of Fe, Mn, $\mathrm{O}$ and $\mathrm{Cu}$ on a $\mathrm{MnS}$ inclusion in carbon steel. The data was obtained from a $1 \mu \mathrm{m}$ field of view. The Auger maps show localized $0.1-0.2 \mu \mathrm{m} \mathrm{Cu}$ impurities on the inclusion surface. Auger map D also shows small features of Fe oxide (in red) on the perimeter of the inclusion as well as Mn oxide patches (in magenta) on the surface. 